\title{
Functional Acidic lonic Liquids as Effective Solvents for the Fractionation of Lignocelluloses
}

\author{
Shi Jia Dong, ${ }^{\mathrm{a}, 1}$ Bi Xian Zhang, ${ }^{\mathrm{c}, 1}$ Peng Zhang, ${ }^{\mathrm{a}}$ Kun Yang Wu, ${ }^{\mathrm{a}}$ Xin Miao He, \\ Wei Ding, ${ }^{\mathrm{a}, *}$ Yun Fei Gao, ${ }^{\mathrm{c}}$ Di Liu ${ }^{\mathrm{b}, \mathrm{c}, *}$ and Xiao Mei Hu ${ }^{\mathrm{a}, *}$
}

\begin{abstract}
There is increasing interest in the application of ionic liquids for the pretreatment and fractionation of lignocelluloses. In this study, a series of functional acidic ionic liquids (ILs) with various heterocyclic organic cations were synthesized. Corn stalks were successfully fractionated into lignin, hemicelluloses, and cellulose when ultrasonically pretreated with ILs at 70 ${ }^{\circ} \mathrm{C}$ for $3 \mathrm{~h}$, and subsequently treated with alkaline extraction. High yields of IL-isolated lignin (18.3\% to $19.6 \%$ ) and (8.3\% to $14.6 \%$ ) were obtained using ILs in the absence and presence of water, respectively. The yield of cellulose ranged from 40.0 to $77.0 \%$ from IL treatments, whereas the yield of hemicelluloses ranged from $1.1 \%$ to $17.3 \%$. Enzymatic hydrolysis of the isolated cellulose residual produced $89.2 \%$ to $94.9 \%$ reducing sugar with $77.8 \%$ to $86.1 \%$ glucose, which corresponded to $80.5 \%$ to $91.4 \%$ enzymatic conversion of cellulose. Syringol and vanillin were found as the main lignin degradation products.
\end{abstract}

Keywords: Ionic liquids; Corn stalks; Fractionation; Lignin degradation products

Contact information: a: Northeast Agricultural University, Harbin, 150030, P.R. China; b: Key Laboratory of Combining Farming and Animal Husbandry, Ministry of Agricultural and Rural Affairs, 150086, P.R. China; c: Heilongjiang Academy of Agricultural Sciences, Harbin, 150086, P.R. China; *Corresponding author: huxiaomei1982@163.com; liudi1963@163.com ${ }^{1}$ These authors contributed equally to this work, both authors are first authors.

\section{INTRODUCTION}

Issues related to climate change and limited fossil-fuel resources have focused investigators to develop sustainable routes for generating energy and valuable chemical products. Abundant lignocellulosic biomass has been identified as a potential renewable resource to produce biofuels. Lignocelluloses are primarily composed of lignin, hemicelluloses and cellulose (Moniruzzaman and Ono 2013), whereby the lignin constituent contributes to the complex and recalcitrant structure of the biomass. Generally, a pretreatment, such as acid, alkali, steam explosion or ammonia fiber explosion process, is used to degrade the recalcitrant structure of the lignocellulosic biomass (Zhang and Shahbazi 2011).

In recent years, ionic liquids (ILs) have been examined as potential alternative pretreatments for lignocellulosic biomass due to their broad liquidity range, high thermal stability, and low vapor pressure (Mora-Pale et al. 2011; Weerachanchai and Lee 2014). Their physical and chemical properties can be directly altered by varying the cation or anion component; hence, ILs can be tailored for specific applications (Hu et al. 2013). A variety of ILs have been used for the pretreatment and fractionation of various lignocelluloses. Rice straw has been reported to be pretreated with cholinium argininate for $12 \mathrm{~h}$ at $90{ }^{\circ} \mathrm{C}$, which resulted in $46 \%$ lignin recovery (based on the starting lignin content). Additionally, $74.6 \%$ glucose was produced after $72 \mathrm{~h}$ of enzymatic 
saccharification of the pretreated rice straw solid (An et al. 2015). Corn stalks have been pretreated with 1-ethly-3-methylimidazolium acetate ([EMIM] $\mathrm{CH}_{3} \mathrm{COO}$ ) for $1 \mathrm{~h}$ at $125^{\circ} \mathrm{C}$, which resulted in $44 \%$ of the original lignin being extracted. $80 \%$ glucose and $50 \%$ glucose were obtained after enzyme reaction of these pretreated corn stalks at 33\% (w/w) and 50\% (w/w) biomass loading, respectively (Li et al. 2009). Moreover, the use of acidic ILs is potentially a sustainable approach of lignocellulosic biomass conversion, which does not require further acid addition. Fibre sludge hydrolysis using hydroxyalkylimidazolium hydrogensulphate as the IL $\left(30 \mathrm{~min}\right.$ at $100{ }^{\circ} \mathrm{C}$ ) produced $29 \%$ reducing sugars (Dong et al. 2014). Hydrolysis of switchgrass in 1-(sulfobutyl)-3-methylimidazolium chloride $\left(\left[\mathrm{HSO}_{3} \mathrm{BuMIM}\right] \mathrm{Cl}\right)$ resulted in $58.1 \%$ reducing sugars under thermal and microwave conditions after $1 \mathrm{~h}$ at $70{ }^{\circ} \mathrm{C}$ followed by treatment with the addition of water for anther 1 $\mathrm{h}$ at $70{ }^{\circ} \mathrm{C}$ (Amarasekara and Shanbhag 2012).

Based on the above review of current studies, more practical investigations regarding the pretreatment of lignocelluloses with functional ILs are necessary. A more efficient protocol is necessary to isolate lignin and to increase carbohydrate saccharification efficiency using low pretreatment temperature (Li et al. 2010; Haykir et al. 2013). The aim of this work was to develop functional acidic ILs as fractionation and pretreatment solvents for lignocellulosic biomass. In a previous investigation, a series of imidazolium salts with various anions were tested; promising results were obtained using 1-methylimidazolium chloride ([HMIM]Cl), with $\mathrm{Cl}^{-}$as the anion for the IL (Zhang et al. 2015). Hence, in this work, a series of ionic liquids that are based on different heterocyclic organic cations paired with the $\mathrm{Cl}^{-}$anion were prepared. These ILs were investigated as pretreatments for corn stock biomass in order to fractionate its constituents. Furthermore, there is limited information concerning lignin degradation products resulting from the ILpretreatment process. In this work, the lignin degradation products were characterized and their relative quantities were analyzed.

\section{EXPERIMENTAL}

\section{Materials}

Chemical reagents and cellulase powder from Aspergillus niger $(10,000 \mathrm{U} / \mathrm{g})$ were obtained from Aladdin Company (Shanghai, China). High-performance liquid chromatography (HPLC) was conducted using an Agilent 1100 HPLC instrument equipped with an Agilent ZORBAX carbohydrate column (Agilent Technologies; Santa Clara, CA, USA). An AV-III 400 MHz NMR spectrometer (Bruker AXS, Inc.; Madison, WI, USA) was used to record ${ }^{1} \mathrm{H}$ NMR and ${ }^{13} \mathrm{C}$ NMR. Reducing sugars and IL acidities were measured using ultraviolet-visible (UV-Vis) spectroscopy with an UV-mini-1240 spectrometer (Shimadzu Corp.; Tokyo, Japan). The constituents of the raw corn stalks (22.47\% lignin, $19.33 \%$ hemicelluloses, $43.21 \%$ cellulose and $0.74 \%$ ash) were determined in accordance to the National Renewable Energy Laboratory (NREL) method (Sluiter et al. 2011). Pyridinium chloride ([HPY]Cl), $N$-methylpyrrolidinium-2-one chloride $([\mathrm{HNMP}] \mathrm{Cl})$ and 1-methylimidazolium chloride $([\mathrm{HMIM}] \mathrm{Cl})$ were synthesized in accordance to (Zhang et al. 2015). 


\section{Synthesis of lonic Liquids}

1-(3-Sulfopropyl)-3-methylimidazolium chloride $\left(\left[\mathrm{MIM}\left(\mathrm{CH}_{2}\right)_{3} \mathrm{SO}_{3} \mathrm{H}\right] \mathrm{Cl}\right)$

1,3-Propanesultone ( $0.4 \mathrm{~mol}$; $99 \%$ purity) was dissolved in ethyl acetate $(200 \mathrm{~mL}$; 99.5\% purity). 1-Methylimidazoline ( $0.4 \mathrm{~mol} ; 99 \%$ purity) was added dropwise into the mixture. The mixture was reacted at room temperature for $24 \mathrm{~h}$. The product was obtained by the evaporation of the ethyl acetate solvent at reduced pressure; the residue was further vacuum-dried at $60^{\circ} \mathrm{C}$ for $24 \mathrm{~h}$. The intermediate product $(0.2 \mathrm{~mol})$ was then treated with concentrated hydrochloric acid $(0.2 \mathrm{~mol})$ at room temperature for $24 \mathrm{~h}$. The resulting product was washed with $20 \mathrm{~mL}$ of diethyl ether and was then dried at $60{ }^{\circ} \mathrm{C}$ for $24 \mathrm{~h} .{ }^{1} \mathrm{H}$ NMR (400 MHz, DMSO- $\left.d_{6}\right): 2.08(t, 2 \mathrm{H}), 2.44(t, 2 \mathrm{H}), 3.84(s, 3 \mathrm{H}), 4.29(t, 2 \mathrm{H}), 7.70(s$, $1 \mathrm{H}), 7.78(s, 1 \mathrm{H})$, and $9.16(s, 1 \mathrm{H})$.

\section{1-(2-Carboxyethyl)-3-methylimidazolium chloride ([MIM $\left.\left.\left(\mathrm{CH}_{2}\right)_{2} \mathrm{COOH}\right] \mathrm{Cl}\right)$}

3-Chloropropionic acid ( $0.4 \mathrm{~mol}$; $98 \%$ purity) and 1-methylimidazole $(0.4 \mathrm{~mol} ; 99 \%$ purity) were added into ethyl acetate $((200 \mathrm{~mL} ; 99.5 \%$ purity). The reaction mixture was stirred at $70{ }^{\circ} \mathrm{C}$ for $24 \mathrm{~h}$. The product was obtained by the evaporation of the ethyl acetate solvent at reduced pressure; the residual was further vacuum-dried at $60{ }^{\circ} \mathrm{C}$ for $24 \mathrm{~h} .{ }^{1} \mathrm{H}$ NMR (400 MHz; DMSO- $\left.d_{6}\right): 2.93(t, 2 \mathrm{H}), 3.86(s, 3 \mathrm{H}), 4.36(t, 2 \mathrm{H}), 7.77(s, 1 \mathrm{H}), 7.86(s$, $1 \mathrm{H}), 9.43(s, 1 \mathrm{H})$, and $12.87(s, 1 \mathrm{H})$.

\section{1-Hydroxypropyl -3-methylimidazolium chloride ([MIM( $\left.\left.\left.\mathrm{CH}_{2}\right)_{3} \mathrm{OH}\right] \mathrm{Cl}\right)$}

The synthesis of $\left[\mathrm{MIM}\left(\mathrm{CH}_{2}\right)_{3} \mathrm{OH}\right] \mathrm{Cl}$ followed a similar protocol as that of [MIM $\left.\left(\mathrm{CH}_{2}\right)_{2} \mathrm{COOH}\right] \mathrm{Cl}$. 3-Chloro-1-propanol (0.2 mol; 98\% purity) was reacted with 1methylimidazole at $70{ }^{\circ} \mathrm{C}$ for $24 \mathrm{~h} .{ }^{1} \mathrm{H}-\mathrm{NMR}$ (400 MHz; DMSO- $d_{6}$ ): 1.89 (quint, $2 \mathrm{H}$ ), $3.31(s, 2 \mathrm{H}), 3.88(s, 3 \mathrm{H}), 4.26(t, 2 \mathrm{H}), 5.23(s, 1 \mathrm{H}), 7.81(s, 1 \mathrm{H}), 7.98(s, 1 \mathrm{H}), 9.62(s, 1 \mathrm{H})$.

\section{Determination of ILs Acidity}

The Hammett method was used to characterize the acidity of ILs at room temperature (Duan et al. 2006; Zhang et al. 2012). The acidity was measured with 4nitroaniline as an indicator (i.e., I) by evaluating the extent of its protonation (i.e., $\mathrm{HI}^{+}$) as a ratio of the concentrations of the acid-base pair (i.e., $\left.[\mathrm{I}] /\left[\mathrm{HI}^{+}\right]\right)$,

$$
H_{0}=p K_{\mathrm{aq}}(\mathrm{I})+\log \left([\mathrm{I}]_{\mathrm{s}} /\left[\mathrm{HI}^{+}\right]_{\mathrm{s}}\right)
$$

where $H_{0}$ is the Hammett acidity function of the IL, $p K_{\text {aq }}(\mathrm{I})$ is that for the indicator (which is 0.99 for 4-nitroaniline), and $[\mathrm{I}]_{\mathrm{s}}$ and $\left[\mathrm{HI}^{+}\right]_{\mathrm{s}}$ are the molar concentrations of the unprotonated and the protonated form of the indicator in solution, respectively.

\section{Fractionation of Corn Stalk}

The fractionation of corn stalk constituents is schematically shown in Fig. 1. Corn stalk powder $(1 \mathrm{~g})$ was added into one of the ionic liquids $(20 \mathrm{~g})$ along with water $(4 \mathrm{~mL})$. The mixture was heated to $70{ }^{\circ} \mathrm{C}$ for $3 \mathrm{~h}$ in an ultrasonicator operating at a $400 \mathrm{~W}$ power level (Zhang et al. 2015). An acetone/water solution (100 mL; 1/1 v/v) was then poured into the IL solution, and the mixture was vigorously agitated. The resulting solid residue, which contained the cellulose-rich fraction, was separated by filtration; the solid was washed with an acetone/water solution $(1 / 1 \mathrm{v} / \mathrm{v})$. The dissolved lignin in the ILs was obtained by evaporating the acetone from Filtrate 1 (Fig. 1); the resulting solid was further washed with water. Filtrate 2 (Fig. 1) was neutralized by the addition of sodium hydroxide. The amount of reducing sugars in the neutralized filtrate was determined by the 
colorimetric method as described by Miller (1959) that used 3,4-dinitrosalicylic acid (DNS).

The cellulose-rich solid was treated with $50 \mathrm{~mL}$ aqueous $\mathrm{NaOH}$ solution $(3 \% \mathrm{w} / \mathrm{w})$ at $80{ }^{\circ} \mathrm{C}$ for $3 \mathrm{~h}$ (Fig. 1). The insoluble residue was separated by filtration, and the solid was washed with water to obtain the purified cellulose fraction. The $\mathrm{pH}$ of Filtrate 3 (Fig. 1) was adjusted to 6.80 with an $\mathrm{HCl}$ solution $(30 \%, \mathrm{w} / \mathrm{w})$. Three volumes of $95 \%$ ethanol were added to the $\mathrm{pH}$-adjusted solution to precipitate the hemicelluloses. Filtrate 4 (Fig. 1) was concentrated under reduced pressure to remove the ethanol. The resulting residual was acidified to $\mathrm{pH} 2$ to precipitate the alkaline lignin (Yang et al. 2012; da Costa Lopes et al. 2013a). All isolated residues were vacuum-dried for $24 \mathrm{~h}$ at $60{ }^{\circ} \mathrm{C}$. All samples were performed for three replicates and their yields were calculated in reference to the untreated corn stock powder:

$$
\text { Residue }(\%)=\frac{\text { Residue }(\mathrm{mg})}{\text { Untreated corn stalk }(\mathrm{mg})} \times 100
$$

\section{Enzymatic Reaction}

Enzymatic hydrolysis of the isolated cellulose $(0.05 \mathrm{~g})$ was carried out in a sodium citrate buffer solution $(5 \mathrm{~mL} ; 0.1 \mathrm{M})$, which was mixed with cellulase $(0.02 \mathrm{~g})$ and $2 \%$ $(\mathrm{w} / \mathrm{w})$ sodium azide aqueous solution $(100 \mu \mathrm{L})$ at a $\mathrm{pH}$ of 4.8 . The reaction mixture was shaken at $150 \mathrm{rpm}$ for $72 \mathrm{~h}$ at $50{ }^{\circ} \mathrm{C}$. The hydrolyzed solution was quenched for $5 \mathrm{~min}$ at $100{ }^{\circ} \mathrm{C}$. The yield of monosaccharide (i.e., glucose) was measured using HPLC (Sluiter $e t$ al. 2011). All samples were performed for three replicates. The enzymatic cellulose conversion was calculated:

$$
\text { Conversion of cellulose }(\%)=\frac{\text { glucose }(\mathrm{mg}) \times \frac{162}{180}+\operatorname{cellobiose}(\mathrm{mg}) \frac{324}{342}}{\operatorname{cellulose}(\mathrm{mg})} \times 100
$$

\section{Analysis of Lignin Products}

Corn stalk powder (100 mg) was added into one of the ionic liquids $(2 \mathrm{~g})$ with the addition of water $(0.4 \mathrm{~mL})$, which was then heated to $70{ }^{\circ} \mathrm{C}$ for $3 \mathrm{~h}$ in an ultrasonicator operating at a $400 \mathrm{~W}$ power level. Benzene $(5 \mathrm{~mL})$ was then added to the mixture to extract all the non-polar compounds. This procedure was repeated three times. The benzene extracts were collected, combined, and concentrated to $1 \mathrm{~mL}$ in volume to achieve the sample. The concentrated extracts were analyzed using gas chromatography-mass spectrometry (GC-MS) with an Agilent 7890 GC plus 4789 MS (Agilent Technologies; Santa Clara, CA, USA) equipped with a HP-5MS chromatographic column (30 m length, $0.25 \mathrm{~mm} \mathrm{ID}$, and $0.25 \mu \mathrm{m}$ packing). A total of $10 \mu \mathrm{L}$ of the sample was injected into the $\mathrm{GC}$ at an inlet temperature of $220{ }^{\circ} \mathrm{C}$. Anthracene- $d_{10}$ was used as the internal standard, and helium was used as a carried gas. Standards were used for each compound to calculate the individual GC response factors.

\section{RESULTS AND DISCUSSION}

A series of functional ionic liquids (ILs) that were based on different heterocyclic organic cations were synthesized with $\mathrm{Cl}^{-}$as the anion. Their chemical structures are depicted in Fig. 1. 
<smiles>Cn1cc[n+](CCCO)c1</smiles>

$\left[\mathrm{MIM}\left(\mathrm{CH}_{2}\right)_{3} \mathrm{OH}\right] \mathrm{Cl}$<smiles>C[NH+]1CCCC1=O</smiles>

$[\mathrm{HNMP}] \mathrm{Cl}$<smiles>Cn1cc[n+](CCC(=O)O)c1</smiles>

$\left[\mathrm{MIM}\left(\mathrm{CH}_{2}\right)_{2} \mathrm{COOH}\right] \mathrm{Cl}$<smiles></smiles>

[HPY]Cl<smiles>Cn1cc[n+](CCCO)c1</smiles>

$\left[\mathrm{MIM}\left(\mathrm{CH}_{2}\right)_{3} \mathrm{SO}_{3} \mathrm{H}\right] \mathrm{Cl}$<smiles></smiles>

[HMIM]Cl

Fig. 1. Chemical structures of ionic liquids

The values of the Hammett acidity function $\left(H_{0}\right)$ for the various ILs are listed in Table 1. Different IL activities (Amax) were derived from their Brønsted acidities.

Table 1. Acidity of lonic Liquids

\begin{tabular}{|c|c|c|c|c|}
\hline Ionic liquid $(\mathrm{IL})$ & $A_{\max }$ & $\mathrm{I}(\%)$ & $\mathrm{Hl}^{+}(\%)$ & $H_{0}$ \\
\hline blank & 1.5068 & 100.00 & 0.00 & - \\
\hline$\left[\mathrm{MIM}\left(\mathrm{CH}_{2}\right)_{3} \mathrm{OH}\right] \mathrm{Cl}$ & 1.5068 & 100.00 & 0.00 & - \\
\hline$\left[\mathrm{MIM}\left(\mathrm{CH}_{2}\right)_{2} \mathrm{COOH}\right] \mathrm{Cl}$ & 1.2524 & 83.12 & 16.88 & 1.75 \\
\hline$\left[\mathrm{MIM}\left(\mathrm{CH}_{2}\right)_{3} \mathrm{SO}_{3} \mathrm{H}\right] \mathrm{Cl}$ & 1.4015 & 93.01 & 6.99 & 2.11 \\
\hline$[\mathrm{HMIM}] \mathrm{Cl}^{\mathrm{H}}$ & 1.4819 & 98.35 & 1.65 & 2.77 \\
\hline$[\mathrm{HPY}] \mathrm{Cl}$ & 1.4569 & 96.69 & 3.31 & 2.46 \\
\hline$[\mathrm{HNMP}] \mathrm{Cl}$ & 1.1351 & 75.33 & 24.67 & 1.47 \\
\hline
\end{tabular}

\section{Cellulose Fraction}

The recovery yields of the cellulose-rich fraction ranged from $51.1 \%$ to $77.0 \%$, depending upon which IL that was used (Table 2). A high yield of the cellulose-rich fraction was obtained with $\left[\mathrm{MIM}\left(\mathrm{CH}_{2}\right)_{3} \mathrm{OH}\right] \mathrm{Cl}$ as the IL pretreatment. On the other hand, pretreatment with $\left[\mathrm{MIM}\left(\mathrm{CH}_{2}\right)_{3} \mathrm{SO}_{3} \mathrm{H}\right] \mathrm{Cl}$ as the IL resulted in a low yield of the celluloserich fraction, which could be attributed to the effectiveness of this IL to remove lignin and hemicelluloses from the recalcitrant biomass. After IL-treatment, the cellulose-rich fraction was extracted with alkali, and resulted in about 39 to $41 \%$ cellulose being recovered from the starting biomass material.

Table 2. Yields of Cellulose and Hemicelluloses

\begin{tabular}{|c|c|c|c|c|c|c|}
\hline \multirow[b]{2}{*}{$\begin{array}{c}\text { Carbohydrate } \\
\text { component }\end{array}$} & \multicolumn{2}{|c|}{$\left[\mathrm{MIM}\left(\mathrm{CH}_{2}\right)_{3} \mathrm{OH}\right] \mathrm{Cl}$} & \multicolumn{2}{|c|}{$\left[\mathrm{MIM}\left(\mathrm{CH}_{2}\right)_{2} \mathrm{COOH}\right] \mathrm{Cl}$} & \multicolumn{2}{|c|}{$\left[\mathrm{MIM}\left(\mathrm{CH}_{2}\right)_{3} \mathrm{SO}_{3} \mathrm{H}\right] \mathrm{Cl}$} \\
\hline & $\begin{array}{c}\text { Ave. yield } \\
(\%)\end{array}$ & SD & $\begin{array}{c}\text { Ave. yield } \\
(\%)\end{array}$ & SD & $\begin{array}{c}\text { Ave. yield } \\
(\%)\end{array}$ & SD \\
\hline Cellulose-rich fraction & 76.98 & 0.4 & 75.16 & 0.8 & 51.10 & 1.2 \\
\hline Cellulose & 41.88 & 0.7 & 39.59 & 0.8 & 35.08 & 0.2 \\
\hline Hemicellulose & 17.33 & 0.4 & 16.76 & 0.3 & 3.31 & 0.2 \\
\hline
\end{tabular}

\section{Lignin Fraction}

As was expected, effective lignin removal (8.34\%) was observed when $\left[\mathrm{MIM}\left(\mathrm{CH}_{2}\right)_{3} \mathrm{SO}_{3} \mathrm{H}\right] \mathrm{Cl}$ was used as the IL-treatment (Table 3). It has been reported that $8.0 \%$ 
lignin was recovered when wheat straw was pretreated with [EMIM] $\mathrm{CH}_{3} \mathrm{COO}$ and subsequently alkali extracted, which was based on the original mass of the wheat straw (da Costa Lopes et al. 2013b). It has been described that 55.6\%, 47.8\%, and $14.6 \%$ of the lignin content was extracted from rice straw when [EMIM] $\mathrm{H}_{2} \mathrm{PO}_{2},[\mathrm{EMIM}] \mathrm{CH}_{3} \mathrm{COO}$, and [EMIM]Cl were used as the IL for pretreatment at $110{ }^{\circ} \mathrm{C}$ for $24 \mathrm{~h}$, which was based on the mass of lignin in the rice straw (Xu et al. 2015). In this work, a low IL pretreatment temperature and a short processing time was employed. Most of the original lignin in the corn straw was dissolved when $\left[\mathrm{MIM}\left(\mathrm{CH}_{2}\right)_{3} \mathrm{SO}_{3} \mathrm{H}\right] \mathrm{Cl}$ was used as the IL, which resulted in a high lignin extraction (8.34\%). Thus, a low yield of alkaline lignin $(4.81 \%)$ was remaining with the cellulose-rich fraction (Table 3 ).

Table 3. Average Yields of Lignin and Reducing Sugars

\begin{tabular}{|c|c|c|c|c|c|c|}
\hline \multirow[b]{2}{*}{ Component } & \multicolumn{2}{|c|}{$\left[\mathrm{MIM}\left(\mathrm{CH}_{2}\right)_{3} \mathrm{OH}\right] \mathrm{Cl}$} & \multicolumn{2}{|c|}{$\left[\mathrm{MIM}\left(\mathrm{CH}_{2}\right)_{2} \mathrm{COOH}\right] \mathrm{Cl}$} & \multicolumn{2}{|c|}{$\left[\mathrm{MIM}\left(\mathrm{CH}_{2}\right)_{3} \mathrm{SO}_{3} \mathrm{H}\right] \mathrm{Cl}$} \\
\hline & $\begin{array}{c}\text { Ave. yield } \\
(\%)\end{array}$ & SD & $\begin{array}{l}\text { Ave. yield } \\
(\%)\end{array}$ & SD & $\begin{array}{c}\text { Ave. yield } \\
(\%)\end{array}$ & SD \\
\hline IL-isolated lignin & 2.86 & 1.1 & 3.16 & 0.2 & 8.34 & 0.8 \\
\hline Alkaline lignin & 7.52 & 0.4 & 8.92 & 0.2 & 4.81 & 0.6 \\
\hline Reducing sugars & 6.89 & 0.5 & 14.41 & 0.5 & 25.25 & 0.7 \\
\hline
\end{tabular}

\section{Hemicelluloses Fraction}

Specifically, 3.3\% of the hemicelluloses were extracted when the corn stalks were pretreated with [MIM $\left.\left(\mathrm{CH}_{2}\right)_{3} \mathrm{SO}_{3} \mathrm{H}\right] \mathrm{Cl}$ (Table 2), whereas $17.3 \%$ of the hemicelluloses were extracted with $\left[\mathrm{MIM}\left(\mathrm{CH}_{2}\right)_{3} \mathrm{OH}\right] \mathrm{Cl}$ treatment. It is possible that the hemicelluloses were hydrolyzed during IL pretreatment due to their acidic nature of these ionic liquids.

The strong acidity of $\left[\mathrm{MIM}\left(\mathrm{CH}_{2}\right)_{3} \mathrm{SO}_{3} \mathrm{H}\right] \mathrm{Cl}$ resulted in the increased hydrolysis of the hemicelluloses, as well as effective lignin removal, from the corn stalks. Hence, high yields of reducing sugars $(25.2 \%)$ were obtained when $\left[\mathrm{MIM}\left(\mathrm{CH}_{2}\right)_{3} \mathrm{SO}_{3} \mathrm{H}\right] \mathrm{Cl}$ was used as the pretreatment IL (Table 3), whereas low yields (6.9\%) were obtained when $\left[\mathrm{MIM}\left(\mathrm{CH}_{2}\right)_{3} \mathrm{OH}\right] \mathrm{Cl}$ was used.

\section{Sample Fractionation by Protic ILs}

On the basis of previous work (Zhang et al. 2015) and experimental results reported in this study, protic ILs seemed more effective; hence, these ILs were further evaluated for their ability to fractionate lignocelluloses. The yields of the fractionated samples are presented in Table 4 . Yields of $40.4 \%$ and $42.8 \%$ cellulose-rich materials were obtained when the corn stalks were treated with $[\mathrm{HNMP}] \mathrm{Cl}$ and $[\mathrm{HPY}] \mathrm{Cl}$, respectively. This observation indicated that most lignin and hemicelluloses were removed during the IL pretreatment.

Lignin acts as a physical barrier for enzymatic hydrolysis of lignocellulosic materials. In this work, $14.6 \%$ lignin (based on the original corn stalk powder) was isolated when using [HNMP]Cl as the pretreatment $\left(70{ }^{\circ} \mathrm{C}\right.$ for $3 \mathrm{~h}$ ), as shown in Table 4. Isolation of $8.5 \%$ lignin (based on the original corn stalk powder) was obtained when using [HPY]Cl as the pretreatment. Isolation of $13.6 \%$ lignin (based on the original corn stalk powder) was reported in our previous work with [HMIM]Cl pretreatment (Zhang et al. 2015). $[\mathrm{HNMP}] \mathrm{Cl}$ is considered to be a promising IL solvent to fractionate lignin from lignocellulosics.

Moreover, when corn stalks were pretreated by [HNMP]Cl and [HPY]Cl, $1.98 \%$ and $1.09 \%$ hemicelluloses were obtained, respectively (Table 4). Most of the 
hemicelluloses were hydrolyzed during the IL pretreatment, which resulted in high yields of reducing sugars (Table 4). This observation is attributed to the strong acidity of these ILs as noted in Table 1.

Interestingly, higher IL acidity is noted with [HNMP]Cl than with [HPY]Cl and $\left[\mathrm{MIM}\left(\mathrm{CH}_{2}\right)_{3} \mathrm{SO}_{3} \mathrm{H}\right] \mathrm{Cl}$ on the basis of the Hammett method (Duan et al. 2006; Zhang et al. 2012). However, a lower yield of reducing sugars was observed with [HNMP]Cl (Table 4), which could be due to its strong acidity causing further degradation of the sugars. HPLC analysis showed that $9.4 \%$ xylose and $8.0 \%$ glucose were isolated with [HPY]Cl treatment, whereas $5.0 \%$ xylose and $4.9 \%$ glucose were isolated with [HNMP]Cl treatment.

Furthermore, it is expected that residual water assisted the hydrolysis of the hemicelluloses, which helped to provide good yields of lignin as the corn stock was decomposed. However, the highest yield of IL-isolated lignin (19.6\%) was obtained with [HNMP]Cl treatment in the absence of water. It has been reported that $[\mathrm{BMIM}] \mathrm{MeSO}_{4}$ is most effective IL to extract lignin (18.8\%) from apple tree prunings when microwaved (Prado et al. 2012). Higher yields of IL-isolated lignin (18.9\% and 18.3\%) were also observed with [HMIM]Cl and [HPY]Cl treatments without water. In this study, water could compete with the anions of the ionic liquids to form hydrogen bonds with lignin (Shill et al. 2011). Therefore, high yields of lignin were observed with ILs treatment in the absence of water.

Table 4. Yields of Cellulose, Hemicelluloses, Lignin, and Reducing Sugars

\begin{tabular}{|c|c|c|c|c|c|}
\hline \multirow[b]{2}{*}{ Biomass fraction } & \multicolumn{2}{|c|}{$[\mathrm{HPY}] \mathrm{Cl}$} & \multicolumn{2}{|c|}{ [HNMP]Cl } & {$[\mathrm{HMIM}] \mathrm{Cl}^{\mathrm{a}}$} \\
\hline & Ave. (\%) & SD & Ave. (\%) & SD & Ave. (\%) \\
\hline Cellulose-rich material & 42.8 & 1.2 & 40.44 & 1.4 & 39.99 \\
\hline Cellulose & 33.36 & 0.2 & 30.07 & 0.9 & 31.21 \\
\hline Hemicellulose & 1.09 & 0.2 & 1.98 & 0.2 & 2.23 \\
\hline IL-isolated lignin & 8.48 & 0.5 & 14.63 & 0.8 & 13.59 \\
\hline Alkaline lignin & 2.44 & 0.4 & 2.31 & 0.2 & 4.81 \\
\hline Reducing sugars & 28.24 & 0.4 & 17.98 & 1.1 & 25.37 \\
\hline
\end{tabular}

\section{Lignin Degradation Products}

The acidic or basic conditions of the treatment may influence the monomeric degradation products of lignin. It has been reported that vanillin is obtained from alkaline treatment (Varanasi et al. 2013). Eugenol (4-allylguaiacol) has been noted to be produced during acid pretreatment (Varanasi et al. 2013). In this work, the lignin degradation products were observed to be dependent upon the IL used. Guaiacol, syringol, and vanillin were observed when [HPY]Cl was used (Fig. 2). Various products that included guaiacol, 4-allylguaiacol (eugenol), 4-ethylguaiacol, syringol, and vanillin were observed when [HNMP] $\mathrm{Cl}$ and $\left[\mathrm{MIM}\left(\mathrm{CH}_{2}\right)_{3} \mathrm{SO}_{3} \mathrm{H}\right] \mathrm{Cl}$ were used during IL pretreatment. It seemed that more degradation products were observed when the IL had a stronger acidity.

As shown in Fig. 3, the amount of lignin degradation products increased as the pretreatment time increased from $3 \mathrm{~h}$ to $10 \mathrm{~h}$. Specifically, high quantities of syringol and vanillin were obtained from the pretreatment with $[\mathrm{HPY}] \mathrm{Cl},[\mathrm{HNMP}] \mathrm{Cl}$, and $\left[\mathrm{MIM}\left(\mathrm{CH}_{2}\right)_{3} \mathrm{SO}_{3} \mathrm{H}\right] \mathrm{Cl}$ for $10 \mathrm{~h}$. 


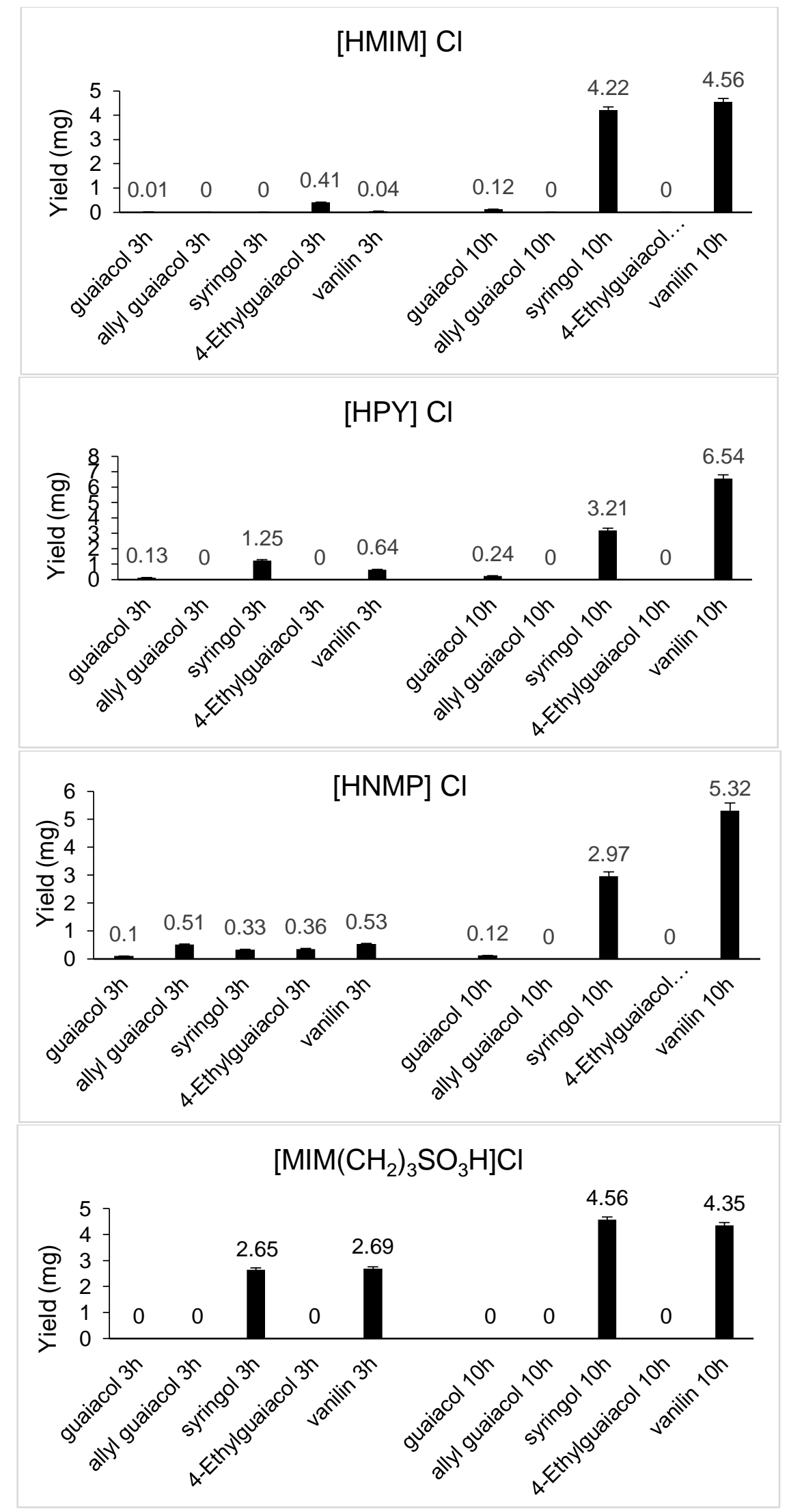

Fig. 2. Lignin degradation products 


\section{Enzymatic Hydrolysis}

The yields from enzymatic hydrolysis of the isolated cellulose from the IL pretreatment processes (as calculated from Eq. 3) are summarized in Table 5. As expected, high yields of glucose and cellobiose, as well as high enzymatic conversion, were obtained with [HNMP]Cl and [HPY]Cl pretreatments. Enzymatic yields of $86.1 \%$ glucose and $14.7 \%$ cellobiose were obtained, along with $91.4 \%$ cellulose conversion, when [HNMP]Cl was used. When [HPY]Cl was used, enzymatic yields of $87.0 \%$ glucose and $13.4 \%$ cellobiose were observed. The effective removal of lignin and hemicelluloses by hydrolysis are attributed to the high digestibility of the cellulose residual by the cellulase treatment.

Enzymatic yields of glucose (77 to 79\%) and cellobiose (10 to 14\%) were noted when $\left[\mathrm{MIM}\left(\mathrm{CH}_{2}\right)_{3} \mathrm{SO}_{3} \mathrm{H}\right] \mathrm{Cl},\left[\mathrm{MIM}\left(\mathrm{CH}_{2}\right)_{3} \mathrm{OH}\right] \mathrm{Cl}$ and $\left[\mathrm{MIM}\left(\mathrm{CH}_{2}\right)_{2} \mathrm{COOH}\right] \mathrm{Cl}$ were used in the IL pretreatment; these yields corresponded to 80 to $83 \%$ cellulose conversion. Protic IL pretreatment of the corn stocks resulted in the complete enzymatic hydrolysis of the isolated cellulose residual.

Table 5. Enzymatic Hydrolysis of Cellulose Residual

\begin{tabular}{|c|c|c|c|c|c|c|c|c|}
\hline \multirow{2}{*}{ lonic liquid (IL) } & \multicolumn{2}{|c|}{ Reducing sugar } & \multicolumn{2}{c|}{ Glucose } & \multicolumn{2}{c|}{ Cellobiose } & \multicolumn{2}{c|}{$\begin{array}{c}\text { Conversion of } \\
\text { cellulose }\end{array}$} \\
\cline { 2 - 9 } & Ave. (\%) & SD & Ave. (\%) & SD & Ave. (\%) & SD & Ave. (\%) & SD \\
\hline$\left[\mathrm{MIM}\left(\mathrm{CH}_{2}\right)_{3} \mathrm{OH}\right] \mathrm{Cl}$ & 89.16 & 1.0 & 78.21 & 0.4 & 10.63 & 0.5 & 80.46 & 0.9 \\
\hline$\left[\mathrm{MIM}\left(\mathrm{CH}_{2}\right)_{2} \mathrm{COOH}\right] \mathrm{Cl}$ & 90.70 & 1.3 & 78.90 & 0.6 & 11.75 & 0.3 & 82.14 & 0.8 \\
\hline$\left[\mathrm{MIM}\left(\mathrm{CH}_{2}\right)_{3} \mathrm{SO}_{3} \mathrm{H}\right] \mathrm{Cl}$ & 89.69 & 2.0 & 77.82 & 0.6 & 14.31 & 0.6 & 83.59 & 1.2 \\
\hline$\left[\mathrm{HPY}_{\mathrm{y} P \mathrm{Cl}}\right.$ & 93.43 & 1.7 & 87.02 & 1.6 & 13.38 & 0.6 & 90.99 & 2.1 \\
\hline$[\mathrm{HNMP}] \mathrm{Cl}$ & 94.89 & 2.7 & 86.12 & 0.6 & 14.66 & 0.3 & 91.40 & 0.9 \\
\hline
\end{tabular}

\section{CONCLUSIONS}

1. Lignocellulosic biomass is a sustainable and valuable feedstock for the large-scale production of biofuels and bioproducts. A series of functional acidic ionic liquids (ILs) with various heterocyclic organic cations were synthesized in this study. [Hnmp]Cl, $[\mathrm{Hpy}] \mathrm{Cl}$ and $\left[\mathrm{HSO}_{3}\right.$ Prmim $] \mathrm{Cl}$ achieved the high yields of lignin and sugars.

2. High yields of IL-isolated lignin (18.3\% to $19.6 \%)$ and $(8.3 \%$ to $14.6 \%)$ were achieved using ILs in the absence and presence of water, respectively. The yield of cellulose ranged from 40.0 to $77.0 \%$ from IL treatments, whereas the yield of hemicelluloses ranged from $1.1 \%$ to $17.3 \%$.

3. Enzymatic hydrolysis of the isolated cellulose residual produced $89.2 \%$ to $94.9 \%$ reducing sugar with $77.8 \%$ to $86.1 \%$ glucose, which corresponded to $80.5 \%$ to $91.4 \%$ enzymatic cellulose conversion.

4. Syringol and vanillin were found as the main lignin degradation products during IL treatment. Functional ILs could be valuable solvents to facilitate the effective conversion of biomass into biofuels. 


\section{ACKNOWLEDGMENTS}

This work was financially supported by the Harbin Science and Technology Innovative Talents Project (2017RAQXJ148), and the University Nursing Program for Young Scholars with Creative Talents in Heilongjiang Province (UNPYSCT-2017021).

\section{REFERENCES CITED}

Amarasekara, A. S., and Shanbhag, P. (2012). "Degradation of untreated switchgrass biomass into reducing sugars in 1-(alkylsulfonic)-3-methylimidazolium Brønsted acid ionic liquid medium under mild conditions," Bioenergy Research 6, 719-724. DOI: 10.1007/s12155-012- 9291-2

An, Y. X., Zong, M. H., Wu, H., and Li, N. (2015). "Pretreatment of lignocellulosic biomass with renewable cholinium ionic liquids: Biomass fractionation, enzymatic digestion and ionic liquid reuse," Bioresource Technology 192, 165-171. DOI: 10.1016/j. biortech.2015.05.064

da Costa Lopes, A. M., João, K. G., Bogel-Lukasik, E., Roseiro, L. B., and BogelLukasik, R. (2013a). "Pretreatment and fractionation of wheat straw using various ionic liquids," Journal of Agricultural Food Chemistry 61, 7874-7882. DOI: $10.1021 / \mathrm{jf} 401980 \mathrm{p}$

da Costa Lopes, A. M., João, K. G., Rubik, D. F. , Bogel-Lukasik, E., Duarte, L. C., Andreaus, J., and Bogel-Lukasik, R. (2013b). "Pre-treatment of lignocellulosic biomass using ionic liquids: Wheat straw fractionation," Bioresource Technology 142, 198-208. DOI: 10.1016/j. biortech.2013.05.032

Dong, Y., Holm, J., Karkkainen, J., Nowicki, J., and Lassi, U. (2014). "Dissolution and hydrolysis of fibre sludge using hydroxyalkylimidazolium hydrogensulphate ionic liquids," Biomass and Bioenergy 70, 461-467. DOI: 10.1016/j.biombioe.2014.09.013

Duan, Z. Y., Gu, Y. L., Zhu, J., Zhang, L. Y., and Deng, Y. Q. (2006). "Protic pyridinium ionic liquids: Synthesis, acidity determination and their performances for acid catalysis," Journal of Molecular Catalyst A: Chemistry 250, 163-168. DOI: 10.1016/j.molcata.2006.01.035

Haykir, N. I., Bahcegul, E., Bicak, N., and Bakir, U. (2013). "Pretreatment of cotton stalk with ionic liquids including 2-hydroxy ethyl ammonium formate to enhance biomass digestibility," Industrial Crops and Products 41, 430-436. DOI: 10.1016/j.indcrop.2012.04.041

Hu, X. M., Zhang, B. X., Yuan, Z., and Hu, B. Z. (2013). "Functional ionic liquids as effective catalysts for the preparation of genistein and daidzein," Journal of Food, Agriculture and Environment 11(2), 193-196. DOI: 10.1234/4.2013.4241

Li, C., Knierim, B., Manisseri, C., Arora, R., Scheller, H. V., Auer, M., Vogel, K. P., Simmons, B. A., and Singh, S. (2010). "Comparison of dilute acid and ionic liquid pretreatment of switch grass: Biomass recalcitrance, delignification and enzymatic saccharification," Bioresource Technology 101, 4900-4906. DOI:

10.1016/j.biortech.2009.10.066 
Li, Q., He, Y., Xian, M., Jun, G., Xu, X., Yang, J., and Li, L. (2009). “Improving Enzymatic hydrolysis of wheat straw using ionic liquid 1-ethyl-3-methyl-midazolium diethyl phosphate pretreatment," Bioresource Technology 100, 3570-3575. DOI: 10.1016/j.biortech. 2009.02.040

Miller, G. L. (1959). "Use of the dinitrosalicylic acid reagent for the determination of reducing sugars," Analytical Chemistry 31, 426-428. DOI:10.1021/ac60147a030

Moniruzzaman, M., and Ono, T. (2013). "Separation and characterization of cellulose fibers from cypress wood treated with ionic liquid prior to laccase treatment," Bioresource Technology 127, 132-137. DOI: 10.1016/j.biortech.2012.09.113

Mora-Pale, M., Meli, L., Doherty, T. V., Linhardt, R. J., and Dordick, J. S. (2011). "Room temperature ionic liquids as emerging solvents for the pretreatment of lignocellulosic biomass," Biotechnology and Bioengineering 108, 1229-1245. DOI: 10.1002/bit.23108

Prado, R., Erdocia, X., and Labidi, J. (2012). "Lignin extraction and purification with ionic liquids," Journal of Chemical Technology and Biotechnology 88, 1248-1257. DOI: $10.1002 /$ jctb.3965

Shill, K., Padmanabhan, S., Xin, Q., Prausnitz, J. M, Clark, D. S., and Blanch, H. W. (2011). "Ionic liquid pretreatment of cellulosic biomass: Enzymatic hydrolysis and ionic liquid recycle," Biotechnology and Bioengineering 108, 511-520. DOI: 10.1002/bit.23014

Sluiter, A., Hames, B., Ruiz, R., Scarlata, C., Sluitter, J., Templeton, D., and Crocker, D. (2011). Determination of Structural Carbohydrates and Lignin in Biomass, Laboratory Analytical Procedure (LAP), Technical Report NREL/TP-510-42618, National Renewable Energy Laboratory (NREL), U.S. Dept. of Energy, Golden, CO, (http://www.nrel.gov/biomass/pdfs/42618.pdf).

Varanasi, P., Singh, P., Auer, M., Adams, P.D., Simmons, B. A., and Singh, S. (2013). "Survey of renewable chemicals produced from lignocellulosic biomass during ionic liquid pretreatment," Biotechnology for Biofuels 6, 14-22. DOI: 10.1186/1754-68346-14

Weerachanchai, P., and Lee, J. M. (2014). "Recyclability of an Ionic liquid for biomass pretreatment," Bioresource Technology 169, 336-343. DOI: 10.1016/j.biortech.2014.06. 072

Xu, J., Wu, B., Hu, L., Wu, Z., Xu, N., Dai, B., and He, J. (2015). "Enzymatic in site saccharification of lignocellulose in a compatible ionic liquid-cellulase system," Chemical Engineering Journal 267, 163-169. DOI: 10.1016/j.cej.2014.12.112

Yang, D., Zhong, L. X., Yuan, T. Q., Peng, X. W., and Sun, R. C. (2012). "Studies on the structural characterization of lignin, hemicelluloses and cellulose fractionated by ionic liquid followed by alkaline extraction from bamboo," Industrial Crops and Products 43, 141-149. DOI: 10.1016/j.indc rop. 2012.07.024

Zhang, B., and Shahbazi, A. (2011). "Recent developments in pretreatment technologies for production of lignocellulosic biofuels," Journal of Petroleum and Environmental Biotechnology 2, 8 pp. DOI: 10.4172/2157-7463.1000108

Zhang, C., Pan, X. Y., Yu, M. J., Jin, L., and Wu, G. (2012). "An efficient method for preparation of propyl gallate using Brønsted acidic ionic liquid $N$-methyl pyrrolidonium hydrosulfate [Hnmp]HSO 4 ," Chemical Engineering Journal 209, 464468. DOI: 10.1016/j.cej. 2012. 08.056 
Zhang, P., Dong, S. J., Ma, H. H., Zhang, B. X., Wang, Y. F., and Hu, X. M. (2015).

"Fractionation of corn stover into cellulose, hemicellulose and lignin using a series of ionic liquids," Industrial Crops and Products 76, 688-696. DOI:

10.1016/j.indcrop.2015.07.037

Article submitted: December 12, 2018; Peer review completed: February 10, 2019;

Revised version received: March 20, 2019; Accepted: April 9, 2019; Published: April 25, 2019.

DOI: $10.15376 /$ biores.14.2.4721-4732 